\title{
Pharmacokinetic Herb-Drug Interactions (Part 1): Origins, Mechanisms, and the Impact of Botanical Dietary Supplements
}

Author

Affiliation
Bill J. Gurley

Department of Pharmaceutical Sciences, University of Arkansas for Medical Sciences, College of Pharmacy, Little Rock, Arkansas, United States

\section{Key words}

- herb-drug interaction

- plant secondary metabolites

- cytochrome P450 enzymes

- transferases

- ATP-binding cassette transporters

- solute carrier membrane transport proteins received Dec. 15, 2011

revised January 23, 2012

accepted January 25, 2012

\section{Bibliography}

Dol http://dx.doi.org/

10.1055/s-0031-1298273

Published online February 9, 2012

Planta Med 2012; 78 :

1478-1489 @ Georg Thieme

Verlag KG Stuttgart - New York .

ISSN 0032-0943

\section{Correspondence \\ Dr. Bill J. Gurley}

Department of Pharmaceutical

Sciences

University of Arkansas for

Medical Sciences

College of Pharmacy

4301 W. Markham St.

Little Rock, Arkansas 72205

United States

Phone: + 15016866279

Fax: + 15015266510

gurleybillyj@uams.edu

\section{Abstract \\ $\nabla$}

Phytochemicals have been components of man's diet for millennia and are believed to have played a significant role in steering the functional development of xenobiotic metabolizing enzymes and transporters within the human gastrointestinal tract. Only recently, however, have plant secondary metabolites been recognized as modulators of human drug disposition. Despite exposure to thousands of structurally diverse dietary phytochemicals, only a few appear to significantly modulate human drug metabolizing enzymes and transporters. In some instances, these interactions may have beneficial effects like cancer pre-

\section{Introduction}

$\nabla$

Since time immemorial, plants have been a rich source of food and medicines. Protracted exposure to an enormous array of plant-derived chemicals (phytochemicals) has had a profound influence on human evolutionary and social development. Unbeknownst to many, evolutionarily ancient phytochemicals lie at the root of man's ability to metabolize modern-day drugs. This is because as humans we have phylogenetically "inherited" the multiplicity of xenobiotic metabolizing enzymes (XMEs) and transporters necessary for detoxifying dietary and environmental chemicals. In effect, the expression and activity of human XMEs and transporters have been shaped by man's exposure to phytochemicals, either as dietary components or as natural medicines.

Modern drugs, many of which are derived from plant sources, are pharmacologically potent single-chemical entities, and XMEs and transporters are important determinants of their absorption, metabolism, distribution, and excretion. A variety of exogenous factors (e.g., diet, drugs, environmental chemicals, etc.) can modulate XME and vention, whereas others may dramatically affect the pharmacokinetics of concomitantly administered drugs. In today's global economy, the opportunity for exposure to more exotic phytochemicals is significantly enhanced. Formulated as concentrated phytochemical extracts, botanical dietary supplements are vehicles for a host of plant secondary metabolites rarely encountered in the normal diet. When taken with conventional medications, botanical dietary supplements may give rise to clinically significant herb-drug interactions. These interactions stem from phytochemical-mediated induction and/or inhibition of human drug metabolizing enzymes and transporters.

transporter activity. These factors, in turn, can affect the efficacy and toxicity of concomitantly administered medications. Most health care professionals and many laypersons are familiar with the concept of drug-drug interactions and their adverse consequences. In addition, many fruits, vegetables, and other foods can interact with conventional medications, a category known as fooddrug interactions. However, with the recent upsurge of herbal dietary supplement usage and the influx of non-Western medical practices (e.g., traditional Chinese medicine, Ayurvedic medicine, Kampo medicine, etc.) that frequently incorporate botanical extracts, a new class of interactions have emerged: herb-drug interactions.

Herb-drug interactions, while ancient in their origins, can have devastating consequences in today's culturally diverse health care environment. In the last decade, several clinically significant herb-drug interactions have been recognized, prompting a surge of research into their cause and mechanism. Essentially two types of herbdrug interactions can be ascribed: pharmacodynamic and pharmacokinetic. Pharmacodynamic herb-drug interactions involve botanicals and 
conventional medications that enhance or negate each other's effects as a result of similar or disparate pharmacologic activity, respectively. For example, weight-loss supplements formulated with Ephedra sinica can negate the effects of many antihypertensive medications due to the sympathomimetic effects of ephedrine alkaloids. Pharmacokinetic herb-drug interactions arise from the ability of phytochemicals or conventional drugs to modulate the activity of XMEs and/or various drug transporters. This review will focus on pharmacokinetic herb-drug interactions, with an emphasis on their sources, causes, and clinical relevancy.

\section{Plant-Animal "Warfare" and the Evolution of Metabolic Defense Mechanisms \\ $\nabla$}

Phylogenetic analyses indicate that the evolution of vertebrate xenobiotic metabolizing enzymes, transporters, and their nuclear receptor regulators began 400 million years ago in a "war" of sorts between terrestrial plants and animals [1-5]. According to the hypothesis, as insects and higher order animals began feeding on plants, the plants, in turn, synthesized toxic phytochemicals as a means of deterring herbivory. Because plants are autotrophs (organisms that synthesize organic compounds from inorganic sources of carbon and energy) incapable of avoiding predation by heterotrophs (organisms that use organic carbon for growth by consuming other organisms), they have invested heavily into chemistry for their survival. One of the principal returns on this investment is the ability to synthesize a myriad of phytochemicals known as plant secondary metabolites (PSMs). Although not part of the primary biochemical pathways of cell growth and reproduction, PSMs are involved in regulation of symbiosis, defense against herbivores and pathogens, and chemical inhibition of competing plant species [6,7]. As plants evolved and adapted to more difficult environmental stresses, so too did the variety, complexity, and toxicity of their resident PSMs. These defense phytochemicals influence herbivores and microbes in a negative fashion by interfering with one, or oftentimes several, molecular targets (e.g., receptors, enzymes, other proteins). The structures of defense phytochemicals appear to have been shaped during evolution in such a way as to mimic the structures of endogenous substrates, hormones, neurotransmitters, or other ligands found in animals - a process termed "evolutionary molecular modeling" [8].

With the ingestion of myriad non-nutrient PSMs over millions of years, mammalian detoxification systems coevolved into an intricate system of XMEs, transporters, and nuclear receptors familiar to most biologists and pharmacologists today. In the case of mammals, detoxification of PSMs is accomplished through combinations of intestinal and hepatic XME-mediated oxidative, reductive, and hydrolytic biotransformations (phase I metabolism), conjugation reactions (phase II metabolism), or transportermediated efflux into the gut lumen or bile (phase III). Over time, continued exposure to multitudes of structurally diverse PSMs appears to have shaped the specificity, capacity, and the "promiscuity" of mammalian transporters and XMEs, rendering them effective at recognizing, transforming, and excreting a multiplicity of xenobiotic structures. This constitutes a mammalian catabolic antidote to plant biosynthetic chemical warfare [1-5].

\section{Plant Secondary Metabolites (PSMs): Plant Synthesis Versus Human Metabolism $\nabla$}

PSMs number in the tens of thousands and include a multiplicity of structurally diverse groups of organic compounds such as polyphenolics, alkaloids, nonprotein amino acids, polyketides, terpenes, steroid and triterpenoid saponins, cyanogenic glycosides, glucosinolates, flavonoids, phenylpropanoids, and others $[6,7,9]$. Central to PSM biosynthesis and accumulation are a host of plant enzymes and membrane transporters, including several whose homologous mammalian forms are familiar to most life scientists: cytochrome P450 enzymes (CYPs), uridine diphosphate glycosyltransferases (UGTs), glutathione S-transferases (GSTs), sulfotransferases (SULTs), ATP-binding cassette transporters (ABC transporters), and solute carrier membrane transport proteins (SLCS).

CYPs, a group of heme-containing metalloenzymes, catalyze a host of crucial biological oxidation reactions in both prokaryotes and eukaryotes. In most cases these reactions can be summarized as activation of the substrate to a reactive intermediate, using electrons from nicotinamide adenine dinucleotide phosphate (NADPH) through the action of NADPH-reductase, followed by introduction of an oxygen atom to form a more polar product. In plants, CYPs are ubiquitous. Fifty-nine families have been identified, and most play an integral role in the synthesis of endogenous PSMs by catalyzing a wide variety of monooxygenation/hydroxylation reactions [10]. Plant CYPs also mediate the oxidative biotransformation of xenobiotics like herbicides/pesticides into more polar, less phytotoxic compounds (phase I metabolism).

A host of UGTS, GSTs, and SULTs catalyze the transfer of polar functional groups - sugars, sulfate, and sulfhydryl, respectively to a wide variety of substrates as a means of increasing hydrophilicity. These polar moieties improve PSM water solubility and transportability. Of the 19 families of plant UGTs, all transfer nucleotide-diphosphate-activated sugars to low-molecular weight aglycone substrates thereby increasing their water solubility and providing access to active membrane transport systems that recognize glucosides but not aglycones [11-13]. SULTs and GSTs participate in several synthetic pathways; however, the extent of their involvement in PSM production has yet to be fully elucidated $[14,15]$. Recently, considerable attention has been paid to plant transferases and their role in propagating resistance to man-made agrochemicals [16]. Resistance develops when plants upregulate both CYPs and transferases in response to continued herbicide exposure [17]. As phase II catalysts, UGTs, GSTs, and SULTs conjugate and further detoxify metabolites of herbicides and pollutants. These conjugated xenobiotics, in turn, are readily sequestered into plant vacuoles where their phytotoxic threat is significantly diminished $[16,17]$.

The $A B C$ transporter proteins are a large and diverse superfamily of mainly membrane-bound proteins ubiquitous in all organisms, the hallmark of which is their ability to derive energy from ATP hydrolysis to actively transport molecules through membranes against a concentration gradient. Plants are a rich source of $A B C$ transporters. More than $130 \mathrm{ABC}$ protein genes have been identified in the genomes of both monocot (Oryza sativa) and dicot (Arabidopis thaliana) plants [18]. Among their various functions is the transport of PSMs within and between cells and cellular organelles. Plants utilize ABC transporters to concentrate PSMs in those tissues vulnerable to herbivory, infection, or other stresses $[18,19]$. Unlike mammals, plants cannot excrete xenobiotic metabolites; therefore, $\mathrm{ABC}$ proteins aid in the transport of glycosy- 
lated metabolites (a phase III process) into vacuoles and the cell wall where they are sequestered and their phytotoxicity neutralized.

SLCs promote the transmembrane movement of molecules without the hydrolysis of ATP. They can function as uniporters if a single type of molecule is transported down an electrochemical gradient, symporters if two molecules are moved simultaneously in the same direction, or antiporters if two molecules are exchanged in opposite directions. Although several SLC families (e.g., SLC7, SLC13, SLC17, SLC22, SLC36, SLC38) have been identified as transporters of positively and negatively charged endogenous substrates essential to primary plant metabolism (e.g., monovalent and divalent cations, amino acids) [20], their role in the transport of PSMs remains largely unknown. Since most members of the SLC22 family in bacteria and animals are polyspecific (i.e., carry multiple substrates) and transport both endogenous and exogenous compounds including many plant-derived drugs, it is likely that several plant SLC22 members also function in the transport of charged PSMs [21]. Taken together, CYPs, UGTs, GSTs, SULTs, as well as ABCs, and perhaps SLC proteins, comprise an important assemblage of enzymes and transporters vital to the synthesis and accumulation of secondary metabolites in plants.

In order to detoxify noxious PSMs, vertebrate animals developed analogous enzymes and transporters within their gastrointestinal tracts, in addition to several heterologous transporters not found in plants (e.g., organic anion transporting polypeptides [OATPs, SLC21s]). Unlike plants, which utilize CYPs, UGTs, and $\mathrm{ABC}$ transporters primarily for PSM synthesis and storage, mammals use them to metabolize and eliminate PSMs.

Of the 18 identified CYP families in humans ( 41 fewer than in plants), only three (CYP1, 2, 3) are involved in the catalytic oxidation of xenobiotics, including PSMs [22]. Within these families, nine specific isoforms constitute the bulk of human phase I reactions: CYP1A2, CYP2A6, CYP2B6, CYP2C8, CYP2C9, CYP2C19, CYP2D6, CYP2E1, and CYP3A4/5. Of these, CYP3A4/5 is perhaps most important as it is involved in metabolizing almost half of all conventional medications. CYP2D6 and CYP2C9 rank second and third, respectively, in the number of drugs affected. These enzymes catalyze a variety of reactions including hydroxylations, dehalogenations, deaminations, N-, S-, and O-dealkylations, epoxidations, N-oxidations, peroxidations, and sulfoxidations, which usually render molecules more polar and easier to excrete. Present at high concentrations in intestinal enterocytes and liver hepatocytes, CYPs are the principal mediators of human phase I metabolism [22].

As for human UGTs, just 10 specific enzymes from two families (UGT1A and 2B) catalyze the bulk of all xenobiotic conjugations [23]. Like CYPs, UGTs are found in high concentrations in the intestine and liver. Unlike their plant homologs, however, human UGTs utilize glucuronic acid as the donor sugar. Glucuronide conjugates are more water-soluble and, in many cases, less bioactive. Five classes of human GSTs catalyze the nucleophilic attack of glutathione on electrophilic substrates, which in the case of lipophilic PSMs, enhances their solubility and elimination [24]. Two families of sulfotransferases, SULT1 and 2, which comprise 10 separate isoforms, carry out the transfer of a sulfate group to dietary PSMs [25]. As with most conjugation reactions, sulfonation usually renders a substrate less toxic. SULTs, however, may activate certain PSMs that are procarcinogens (e.g., estragole, safrole) [26]. Collectively, the conjugative capabilities of UGTs, GSTs, and SULTs constitute the bulk of human phase II metabolism.
Approximately $50 \mathrm{ABC}$ transporters have been discovered so far in humans, 14 of which are related to the efflux of xenobiotics from various cell types $[27,28]$. ABCs are expressed in a variety of tissues, often in normal epithelial cells such as the brush border membrane of intestinal enterocytes, the canalicular surface of hepatocytes, and the apical membrane of proximal renal tubular cells $[27,29]$. ABCs in these tissues are believed to play protective roles; intestinal $A B C s$ limit the absorption of xenobiotics, whereas liver and kidney ABCs facilitate elimination of xenobiotics through biliary and urinary excretion, respectively [30]. Among the most studied ABC transporters is ABCB1, also known as P-glycoprotein (P-gp) or multidrug resistance protein 1 (MDR1). Highly expressed in the intestine, liver, and brain, ABCB1 functions as an efflux pump exhibiting broad substrate specificity, including affinity for many PSMs [27-30]. It is now well recognized that the phase III safeguard provided by ABCs works in concert with phase I and phase II enzymes to restrict systemic PSM exposure.

Two solute carrier families (SLC21 and SLC22) function in humans as uptake transporters for a variety of endogenous and exogenous anions, cations, and zwitterions [27]. Specific members of these families may be found on the apical and/or basolateral surfaces of cell membranes in a host of tissues [27,30]. It is as substrates for these polyspecific SLCs that many PSMs gain access to intestinal enterocytes and hepatocytes, at which point they can be acted upon by XMEs and ABC transporters.

As a general rule, human XMEs and transporters exhibit broad substrate specificity, a characteristic that may be an adaptation to the selective pressures of an evolutionarily long and varied exposure to dietary PSMs [31]. In contrast, plant CYPs display much narrower substrate specificities $[17,32]$. Such differences underscore the discrete roles these proteins play in plants, where they function in PSM synthesis and accumulation, versus humans, where their purpose is to metabolize and excrete PSMs. At first glance, this impressive collection of plant and animal proteins appears to be working at cross-purposes, yet they actually share a common goal of defense of the organism.

\section{PSM-mediated modulation of human drug disposition}

When consumed as part of the normal diet or as constituents in dietary supplements, many PSMs have the ability to modulate (inhibit or induce) the activity of human XMEs and transporters $[33,34]$. For most transporters, transferases, and CYPs, PSMmediated inhibition at the protein level can be broadly classified as competitive or noncompetitive. Competitive inhibition occurs when PSMs simply compete with another substrate (e.g., drug) for either a transporter's binding domain or an enzyme's catalytic pocket, whereas noncompetitive inhibition involves binding at a position other than the active site (i.e., an allosteric site). In both competitive and noncompetitive inhibition, the effects are reversible. PSMs may, however, also produce irreversible inhibitory effects, to which CYPs are particularly susceptible [33]. Known as mechanism-based inhibition, this process involves catalytic activation of the PSM to produce a reactive metabolite (i.e., metabolic intermediate or MI) that irreversibly binds to and inactivates the CYP. Compared with reversible inhibition, mechanism-based inhibition of CYPs by PSMs more frequently cause clinically important herb-drug interactions, as the inactivated enzyme has to be replaced by newly synthesized CYP protein [33].

Induction of XMEs and transporters by PSMs generally occurs via ligand-activated transcription factors [35]. Distributed in the liver, intestine, and other tissues, these cytosolic proteins, or nu- 
clear receptors, can sense a wide variety of xenobiotics and act as master regulators of XME and transporter expression [36]. Ligand bound nuclear receptors form heterodimers with related coactivator proteins and translocate to the cell nucleus. There, these protein complexes bind several distinct DNA elements of XME and transporter genes to activate their transcription. Among the human nuclear receptors that recognize PSMs are the aryl hydrocarbon receptor $(A h R)$ - a regulator of CYP1A2 and ABCB1, the pregnane xenobiotic receptor (PXR) - a promiscuous xenosensing regulator of CYP2A, CYP2B, CYP2C, CYP3A, UGT1A, SULT2A, GSTs, various $A B C$ transporters, and the constitutive androstane receptor (CAR), which directs the expression of CYP2B6, CYP2C9, CYP3A4, UGT1A, SULT2A, GSTs, and certain ABC isoforms. Considerable crosstalk also occurs among the nuclear receptors as they can share ligands, DNA-binding elements, and coactivators [37]. Simultaneously with CYP and $\mathrm{ABC}$ upregulation, ligand bound nuclear receptors may decrease SLC expression, a response in line with their function as xenosensors [27,37]. Of the many XMEs and transporters under the control of nuclear receptors, CYP2E1 is an exception. Induction of CYP2E1 occurs post-transcriptionally, presumably by stabilization of enzyme degradation [38]. In short, various regulatory processes ensure optimized XME and transporter expression in the milieu of PSM exposure.

The heterogeneous nature of PSMs and their effects on human $\mathrm{XME}$ and transporter activity is exemplified by the sulfur-containing glucosinolates found in cruciferous vegetables. When ingested in sufficient quantities, vegetable glucosinolates are converted to isothiocyanates, which can inhibit certain CYP isoforms (e.g., CYP1A2, CYP2E1) while inducing the activity of various GSTs and UGTs [39]. Other noteworthy examples include hyperforin, a prenylated phloroglucinol found in St. John's wort (Hypericum perforatum), and isoquinoline alkaloids present in goldenseal (Hydrastis canadensis) [33]. Hyperforin, a potent PXR ligand, induces several CYPs, UGTs, and ABC transporters; while the isoquinoline alkaloids berberine and hydrastine are mechanismbased inhibitors of CYP3A4 and CYP2D6. From an evolutionary viewpoint, it is understandable why $\mathrm{XME}$ and $\mathrm{ABC}$ transporter induction can be beneficial to mammals, as this mechanism would facilitate elimination of potentially harmful dietary PSMs. From the plant's perspective, an ability to metabolically activate PSMs into a more toxic species by stimulating XME expression in animals may be just one course of action in a multiple defense strategy.

Inhibiting animal XMEs may be another favorable defense tactic for plants, especially if the absorption of one group of PSMs is facilitated through competitive or noncompetitive inhibition mechanisms produced by a second group. A multitude of unique PSMs can be present in a given plant species and, when consumed, these selected chemical entities may work in concert through XME or ABC transporter inhibition - and possibly induction - to promote the exposure of one PSM at the expense of another. An example familiar to most pharmacologists is the mechanism-based inhibition of human intestinal CYP3A4 by furanocoumarins present in Rutacea species (e.g., grapefruit, Seville orange) [40]. When concomitantly ingested, the citrus furanocoumarins bergamottin and 6',7'-dihydroxybergamottin can significantly increase the oral bioavailability of various CYP3A4 drug substrates [41]. However, it remains to be determined if the absorption of other grapefruit PSMs are similarly affected by the inhibitory effects of furanocoumarins. In itself, grapefruit juice is not harmful to humans, but its ability to inhibit CYP3A may have evolved as a successful defense ploy against other species.
Of course, PSMs generated by plants in response to stresses imposed by one species may actually prove beneficial when ingested by another species. Fruits and vegetables as part of the human diet are a case in point. Due to the variety of fruits and vegetables consumed by humans, PSM-mediated inhibition of XMEs and transporters may have salutary effects. For example, CYP2E1 catalyzes the activation of certain nitrosamines and other environmental carcinogens $[42,43]$. Inhibition of CYP2E1 activity and expression by organosulfur compounds present in garlic was correlated with a reduced tumor incidence in rat models of carcinogenesis involving nitrosamines $[44,45]$. Moreover, allyl sulfides in garlic oil and isothiocyanates from watercress have been shown to selectively inhibit human CYP2E1 in vivo $[46,47]$. While not conclusive, such effects likely represent one of many mechanisms to explain why diets rich in sulfur-containing PSMs appear to be chemopreventative $[39,48]$. Similar effects are likely related to interactions between PSMs and other XMEs and transporters.

The aforementioned examples illustrate that defensive strategies devised by both plants and animals, as a result of their continued "warfare", have garnered biological defeats and victories for both sides. From the human perspective, the savage nature of certain battles in this "war" is still visible within the genetic code.

\section{Dietary PSMs and human CYP polymorphisms}

For thousands of years, plants have been an integral component of the human diet and, as a result, man has developed an efficient means for detoxifying plant-derived xenobiotics. Several lines of evidence, however, point to man's continued exposure to unique phytochemicals, or lack thereof, as a possible mechanism for establishing genetic polymorphisms in XMEs [31,49,50]. Allelic variants in CYPs found among various ethnic groups are believed attributable, at least in part, to diets enriched by plants indigenous to specific geographic regions of the world [50]. Support for this hypothesis is coupled to the historical use of nitrogenous plant alkaloids among peoples of North Africa and the Middle East and the prevalence of the CYP2D6 ultra-rapid metabolizer (UM) phenotype in these populations [51].

CYP2D6 is an important human CYP isoform with regard to xenobiotic metabolism in that it catalyzes the metabolism of many nitrogen-containing drugs and has a high affinity for plant alkaloids [51,52]. Two other characteristics are also notable for CYP2D6: the enzyme is polymorphic, and it is not inducible [51]. Allelic variants of the CYP2D6 gene yield a range of xenobiotic metabolizing phenotypes: poor metabolizer (i.e., homozygous for inactive alleles), intermediate metabolizer (heterozygous for an active and inactive allele), extensive metabolizer (homozygous for active alleles), and ultra-rapid metabolizer (multiple copies of active alleles). Generally, most polymorphisms in CYP genes are of low frequency, but several are found with relatively high frequency in certain populations. For example, the incidence of the CYP2D6 UM phenotype is approximately $10 \%, 20 \%$, and $30 \%$ for people originating from Turkey, Saudi Arabia, and Ethiopia, respectively, whereas UMs are uncommon in Northern Europe (1$2 \%)$ and virtually absent in Asia $[51,53]$. This polymorphism occurs at rates far higher than can be accounted for by random mutation events and is believed to reflect selection pressures resulting from early exposure to local edible and medicinal plants [50, 53,54]. Perhaps not coincidentally, North Africa and the Middle East are host to many plants whose nitrogenous alkaloids are CYP2D6 substrates. The opium poppy, a source of nitrogen-containing opioids, is native to the Turkish region, and khat (a plant 
containing amphetamine-like compounds) is native to Northeast Africa and is ubiquitously chewed in Ethiopia and the Arabian Peninsula [54].

That CYP2D6 is not inducible may have rendered it more susceptible to dietary pressures that select for expression of multiple copies of functional alleles. This adaptation would have allowed subjects to more efficiently detoxify plant toxins. It has been proposed that this selection pressure occurred in Northeast Africa approximately 5000-10000 years ago during periods of starvation, which favored survival of those subjects exhibiting the UM phenotype $[53,55]$. Such a selection would have increased the number of plants available to provide useful food. Subsequent migrations to the Mediterranean area may also explain the high frequency of UMs in Southern Europe [51,55].

The reasons for mutant CYPs, which gave rise to slow-metabolizer phenotypes, are not known, but it is possible that during the course of human evolution the requirement for detoxification of nitrogenous plant alkaloids became unnecessary due to dietary changes. Thus, allelic variants, which would have spontaneously arisen, may have become established in the human genome due to lack of coevolutionary pressures to suppress them [31]. In other words, elimination of dietary pressures that had been selected for functional XMEs now favored selection of polymorphs with reduced function. Similar arguments have been made to explain the frequency of CYP2A6-reduced function alleles among Japanese [54], the slow-acetylator phenotype for $\mathrm{N}$-acetyltransferase among Caucasians [50], and the ethnic distribution of glucose-6phosphate dehydrogenase mutations [50]. One prominent researcher in the field provided a succinct summation of the theory: "It is very likely...that 6000 years of a diet principally of goat meat and milk products - compared with that principally of tropical fruits and plants - might lead to XME polymorphisms" [50].

Over the last ten thousand years, the advent of agricultural practices and plant domestication has, in many instances, reduced the number and type of toxic PSMs commonly encountered in the human diet, and increased the content of beneficial phytochemicals [56]. This circumstance has become even more pronounced in the last 100 years with the global distribution of domesticated grains, fruits, and other plant foodstuffs, in effect leavening man's exposure to more common PSMs. Today, many PSMs present in fruits and vegetables (e.g., flavonoids and polyphenolics) are thought to possess beneficial health effects, especially with regard to the prevention of chronic diseases (e.g., cancer, cardiovascular disease, diabetes, etc.) [57-62]. As mentioned previously, modulation of XMEs and transporters are among the various pharmacologic mechanisms underlying the salutary effects of fruit and vegetable consumption. Yet, when taken concurrently with conventional medications, these mechanisms may give rise to clinically important drug interactions.

The purpose of the present review, however, is not to address drug interactions related to ingestion of PSMs present in common fruits and vegetables, but rather to evaluate the pharmacokinetic herb-drug interaction potential of several popular botanical dietary supplements, with an emphasis on their sources, causes, and clinical relevancy.

\section{DSHEA, Dietary Supplements, and the Risk for Herb-Drug Interactions \\ $\nabla$}

Botanicals have been the archetype for medicines since ancient times, and still today they serve as sources for modern drug discovery. While their use in contemporary American medicine has all but disappeared, they still underpin the philosophies of traditional Chinese medicine, Ayurvedic medicine (India), and Kampo medicine (Japan). Up until the early 20th century, monographs for botanicals and botanical extracts composed a significant part of the United States Dispensatory and the U.S. Pharmacopeia, but the coming of the modern drug industry supplanted their use, relegating them to relative obscurity. That is until 1994, when the United States Congress passed the Dietary Supplement Health and Education Act (DSHEA), legislation that characterized botanical extracts as dietary supplements [63]. A dietary supplement, as defined by the act, is "a product (other than tobacco) added to the total diet that contains at least one of the following ingredients: a vitamin, mineral, herb or botanical, amino acid, metabolite, extract, or combination of any ingredient described previously."

Formulated as tablets, capsules, etc., they are sold alongside conventional over-the-counter (OTC) medications in retail outlets; and while not intended to treat, cure, mitigate, or prevent any disease, many consumers view dietary supplements as substitutes for conventional medications [64]. Since their introduction in 1994, dietary supplements have gained a significant foothold in the American health care system. As testament to their popularity, $18 \%$ of U.S. adults regularly consume botanical supplements, spending more than $\$ 14$ billion annually $[65,66]$. Current surveys indicate that $20-30 \%$ of prescription drug users take medications concomitantly with herbal supplements, oftentimes without notifying their physician or other health care professional $[67,68]$. Moreover, $70 \%$ of regular users of botanical supplements also take prescription medications [67]. Prospects for herb-drug interactions, therefore, are considerable.

Most vulnerable to these types of interactions are the elderly. Adults aged 65 years or older are the greatest consumers of prescription medications, and concurrent use of multiple medications (polypharmacy) is common in this population [69]. When coupled with age-related changes in drug disposition - a normal consequence of growing older - polypharmacy predisposes the aged to adverse drug reactions as well as drug-drug interactions. Over the last five years in the U.S., a noticeable increase in botanical supplement usage has occurred among seniors [68,70], with as many as $40-70 \%$ of survey respondents reporting regular use of herbal products $[68,71,72]$. Surveys also indicate that less than $50 \%$ of Americans over the age of 65 disclose their herbal supplement use to physicians $[71,73,74]$. This combination of polypharmacy, botanical supplementation, and reticence places the elderly at an increased risk of herb-drug interactions.

\section{Uncertainty in Predicting and Interpreting Herb-Drug Interactions \\ $\nabla$}

The molecular mechanism(s) underlying most herb-drug interactions and the clinical magnitude of their effects are oftentimes difficult to discern. The vagaries of these processes are rooted in both plant and human physiology. Factors influencing whether herb-drug interactions are of clinical concern include variable enteric CYP3A/ABC content and activity, human pharmacoge- 
netics, phytochemical synergy, irregularities in phytochemical content, and incongruities between in vitro predictions and in vivo realities. Other confounders unrelated to physiological issues involve adulteration or contamination of botanicals with prescription medications or other toxins.

\section{Variability in enteric CYP3A/ABC content/activity}

CYP3A4 catalyzes the biotransformation of more drugs than any other CYP isoform. Highly expressed in the liver and small intestine, it is a major determinant of drug bioavailability. ABC efflux transporters, localized on the apical surface of intestinal enterocytes, work in concert with CYP3A to regulate drug absorption. Intestinal CYP3A and $\mathrm{ABCB} 1$ expression can be extremely variable, with baseline enteric content/activity differing among individuals by as much as 8 - to 10 -fold, respectively [75,76]. Intersubject variability in protein expression is also evident for an assortment of SLC transporters as well [77]. Such large interindividual variabilities can have profound effects on drug pharmacokinetic profiles and must be taken into consideration when interpreting clinical herb-drug interaction studies, especially those involving CYP3A4/ABCB1 substrates.

\section{Human pharmacogenetics}

Pharmacogenetics - the study of genetic variation on human drug response - is gaining attention for its impact on the outcome of herb-drug interaction studies [78]. Individuals expressing mutant XME or transporter alleles may respond to the modulatory effects of PSMs differently than subjects homozygous for the wild-type allele. Ginkgo (Gingko biloba), garlic (Allium sativum), and milk thistle (Silybum marianum) are examples of botanicals whose effects on drug disposition appear to correlate with allelic variants. In a cohort of Chinese volunteers, Ginkgo biloba supplementation significantly enhanced omeprazole hydroxylation in a CYP2C19 genotype-dependent manner [79]. For those subjects exhibiting a poor metabolizer CYP2C19 phenotype, ginkgo-mediated induction was more pronounced. Allicin, an active ingredient in garlic, increased the area under the plasma concentration-time curve (AUC) for omeprazole in a genotype-dependent manner for homozygous CYP2C19*1 and heterozygous CYP2C19*1/*2 carriers, but subjects homozygous for CYP2C19*2 were not affected [80]. An increase in losartan AUC was also noted for volunteers with the CYP2C9*1/*1 genotype, but not in CYP2C9*1/*3 carriers when milk thistle (Silybum marianum) flavanolignans (e.g., silymarin, $140 \mathrm{mg}$ ) were administered thrice daily for 14 days [81]. From these examples, it is clear that certain herb-drug interactions may be genotype dependent.

\section{Phytochemical synergy}

Pharmacologic synergy is believed central to PSM defense mechanisms [82,83]. In combating enemies, particularly those having evolved resistance to a specific PSM, plants often utilize multiple phytochemicals whose total effect is greater than the sum of their individual actions. It is believed that phytochemical synergy also underpins the health benefits of fruits, vegetables, and medicinal plants [82,83], and likely orchestrates the interplay among XMEs and transporters when plant-based foods and drugs interact. This purported synergy may involve protection of an active substance from degradation by enzymes; it may facilitate transport across membrane barriers by overcoming multidrug resistance mechanisms; it may improve the aqueous solubility of lipophilic compounds, or involve a combination of measures. Numerous in vitro studies reveal an abundance of botanical extracts and purified phytochemicals capable of modulating XME and transporter activity [84-121]. Considering the wide array of PSMs to which intestinal enterocytes are subjected, synergy among components, or at least additivity, may explain the enhanced effects botanicals often exhibit relative to purified phytochemicals [103]. As an illustration of phytochemical pharmacodynamic synergy, investigators recently demonstrated that the antidepressant properties of St. John's wort extracts hinged upon the joint activities of several structurally unrelated PSMs (e.g., hypericins, flavonol glycosides, and hyperforins) [122]. This pharmacodynamic synergy appeared linked to an assemblage of "co-effector" phytochemicals (e.g., procyanidin dimmers, procyanidin trimers, polyphenols) whose combined effects at improving the solubility and transport of hypericin, a highly lipophilic napthodianthrone, produced a pharmacokinetic synergy.

Simply put, when plant foods or extracts are ingested along with highly purified, single-ingredient drug products, cellular defense mechanisms may be overwhelmed by a plethora of chemically diverse PSMs working in concert to affect drug uptake and disposition. Oftentimes, the winner of these isolated "battles" in the "war" between plants and animals will dictate the clinical magnitude of an herb-drug interaction.

\section{Phytochemical content variability}

When comparing results of clinical herb-drug interaction studies, variability in the phytochemical content of products evaluated is a common confounder. It is not unusual for large variations in phytochemical composition to exist among different brands of the same botanical species and amid batches of the same brand [123-125]. This drawback, often overlooked by clinical scientists, is dependent upon the plant species utilized (e.g, Echinacea purpurea vs. E. pallida), country of origin, production practices (e.g., cultivation vs. collection), climatic conditions, time of harvest, post-harvest storage conditions, plant part utilized (e.g., fruit, leaves, stem, root), extraction procedure (e.g., aqueous vs. nonaqueous solvent extraction), and extract dosage form (e.g., powder, tablet, capsule, liquid) in creating the final product. Variations in phytochemical type and content are perhaps more important to the safety and efficacy of botanical dietary supplements than for plant-based foods [126]. Unlike fruits and vegetables, where phytochemical exposure is dependent upon the quantity ingested, exposure to PSMs in herbal products is dependent on the dose and type of preparation ingested. Botanical products come in a number of different dosage forms including teas (for aqueous extracts), tinctures (alcohol extracts), and capsules and tablets of extracts (aqueous, ethanolic, $\mathrm{CO}_{2}$, or other extraction solvents). Among extracts, the type of solvent used will determine the PSM profile of a finished product. Many products contain the same relative amounts of PSMs found in the unprocessed herb while others are formulated to contain added levels of "active" compounds. Such concentrated or otherwise modified extracts are more likely to influence XME and/or transporter activity and to produce interactions with concomitantly administered drugs.

Plant extracts are not created equally. Extracts "standardized" to contain known quantities of specific phytochemicals may differ considerably in the content of "nonstandardized" components $[127,128]$. Standardized extracts may also yield dissimilar quantities of PSMs when formulated into various dosage forms by multiple manufacturers [123-125,129]. Dissimilar PSM profiles, in turn, produce disparate effects on XMEs [130]. Variability in manufacturer's recommended dose and duration of use are also 
factors for consideration, not to mention the ingestion of multiple supplements. Moreover, inconsistencies in dosage form performance (e.g., disintegration, dissolution) can also affect the rate and extent at which PSM concentrations reach the intestinal lumen [131]. This is exemplified by an examination of nine separate milk thistle formulations whose 1 -hour percent release rates of silibinin into an aqueous buffered solution $\left(\mathrm{pH} 7.5,37^{\circ} \mathrm{C}\right)$ ranged from $0-85 \%$ [132]. Brand-related disparities in phytochemical release rates have been observed for other botanical supplements $[133,134]$. At present, pharmacopeial recommendations for dissolution tests as a quality control measure for dietary supplements are limited to only a few botanicals [135]. Only recently have good manufacturing practices (GMPs) for dietary supplements been promulgated in the United States [136]; nevertheless discrepancies in actual phytochemical content versus the stated label claim continue to plague many products. Such discrepancies may profoundly affect the interpretations of clinical herb-drug interaction studies; especially, if a botanical supplement's phytochemical content is not independently verified.

\section{In Vitro Predictions and In Vivo Realities}

$\nabla$

Most of the published research on herb-drug interactions has focused on in vitro evaluations of botanical constituents in microsomal systems, supersomes, expressed enzymes or cell culture systems such as transfected cell lines, primary cultures of human hepatocytes, and tumor derived cells. As a result, a substantial body of literature - of which only a modest portion is referenced here - indicates that many botanicals and individual phytochemicals appear capable of modulating XME and transporter activity [84-121]. In addition to in vitro studies, numerous in vivo investigations have been carried out in both animals and humans. Quite often, significant discrepancies exist between in vitro predictions and in vivo realities. Moreover, the results of animal experiments may not always coincide with clinical findings. Because the study of herb-drug interactions involves a host of complexities, each approach has its advantages and limitations [126, $137,138]$.

\section{In vitro methods (advantages and limitations)}

In vitro studies are valuable for evaluating both purified phytochemicals and multicomponent extracts. They can provide mechanistic information about potential interactions and are relatively simple and inexpensive to perform. Several limitations, however, hamper their utility as predictors of in vivo responses [127,137, 138]. First, most methods employ solubilizing agents (e.g., dimethylsulfoxide [DMSO], ethanol, acetonitrile) to facilitate exposure and uptake of poorly water-soluble phytochemicals into cells or microsomes. This practice, however, can exaggerate experimental findings because solubility issues that otherwise limit phytochemical bioaccessibility in vivo are circumvented. Second, phytochemical concentrations necessary to modulate enzyme or transporter activity often exceed those achieved in vivo. Third, studies examining purified compounds may not reflect the phytochemical complexity typical of extracts that may contribute to the net inhibitory or inductive effects observed. For example, many lipophilic aglycones examined in vitro exist as hydrophilic glycosides in extracts, a condition that may limit cellular uptake in vivo. Fourth, many PSMs undergo extensive intestinal and/or hepatic metabolism, a condition that may affect their net modulatory effects in vivo. Despite the limitations described above, in vitro screening methods can identify botanicals/phytochemicals with inhibitory or inductive potencies that may warrant further examination in vivo, even though few significant drug interactions have actually been discovered or accurately predicted with in vitro methods to date $[137,138]$.

\section{In vivo animal methods (advantages and limitations)}

Herb-drug interaction studies conducted in small animals (e.g., mice, rats, dogs, etc.) have advantages of being less expensive than human clinical studies and can often provide an initial assessment of bioavailability either for phytochemicals in pure form or in the context of a complex extract. Limitations of animal studies are that large, nonphysiological doses are often administered and, due to species variation in metabolism and transport, results are rarely generalizable to humans $[126,137]$.

\section{In vivo human studies (advantages and limitations)}

The importance of in vivo human studies for investigating herbdrug interactions came to the forefront in 2000 when a succession of clinical case reports revealed that St. John's wort drastically reduced plasma concentrations of the immunosuppressant cyclosporine, precipitating graft rejection in organ transplant recipients [139-142]. Because cyclosporine is a substrate of CYP3A4 and ABCB1, St. John's wort was suspected of inducing the activity of these two important drug disposition proteins. Coincident with the case study series, conflicting in vitro studies indicated that St. John's wort either inhibited CYP3A4 [84] or was a potent ligand of the orphan nuclear receptor PXR [143,144]. Only after a series of prospective clinical studies incorporating other CYP3A4 and ABCB1 substrates, did it become clear that St. John's wort was indeed a potent inducer of these regulatory proteins [145-149].

Since 2000, substantial numbers of prospective clinical studies incorporating a variety of experimental designs have been conducted (for recent reviews, see references [150-160]). Typically, subjects receive a single dose of a test drug or a cocktail of drugs that are markers for various enzymes. Individual drug phenotypes (e.g., pharmacokinetic profiles, drug/metabolite ratios) are then determined $[46,137]$. This is followed by daily multiple dosing of the botanical supplement, usually for 14-30 days, whereupon phenotypic profiling of the test drugs is repeated. A comparison of pre- and post-treatment pharmacokinetic parameters or phenotypic measures is then used to gauge how XME or transporter activities were affected. The principal advantage of this approach is that it offers a definitive means of assessing the magnitude and implications of herb-drug interactions.

Several common oversights, however, can influence the outcome and interpretation of human studies. First, because botanical supplements often exhibit significant brand-to-brand and lotto-lot variability, commercially available products must be analyzed independently for phytochemical characterization and content. Simply relying on stated label claims is insufficient. Second, disintegration and dissolution characteristics for specific dosage forms should be conducted prior to study implementation. Dosage forms failing to properly disintegrate or release their purported "marker" compounds within a reasonable time period will preclude any meaningful results. Failure to address these issues makes it difficult to extrapolate from one formulation to another. Third, an assessment of phytochemical bioavailability or detection of marker compounds in circulating plasma or urine provides evidence of exposure as well as subject compliance. Although desirable, this prerequisite is often limited by the pau- 
city of validated analytical methods available for measuring unique phytochemicals and/or their metabolites in biologic fluids. Furthermore, due to the complexity of botanical extracts, detection of specific marker compounds in biologic fluids may not necessarily establish an individual phytochemical as a causative agent in an observed phenotype change. Fourth, very few studies incorporate positive controls for inhibition (e.g., clarithromycin as CYP3A4/ABCB1 inhibitor) or induction (e.g., rifampin as a CYP3A4/ABCB1 inducer) as a means of gauging clinical relevance $[161,162]$. This last aspect provides a practical framework from which to compare and interpret the clinical relevance of human herb-drug interaction studies.

Recently, the U.S. Food and Drug Administration (FDA) released a set of guidelines for interpreting the clinical significance of drug interactions in the U.S. [163,164]. These guidelines are based on clinical experience with several well-defined drug interactions, mainly involving the inhibition of CYP3A4. For this interaction mechanism, the benzodiazepine midazolam (MDZ) was shown to be a reproducible probe allowing quantitative determination of the interaction potential of an enzyme inhibitor. For MDZ, the extent of interaction can be measured in the form of an increase in the AUC. The guidelines propose that inhibitors producing changes in MDZ AUC amounting to less than a 2-fold increase should be classified as "weak". Increases ranging from 2- to 5fold were classified as "moderate", whereas a "strong interaction is marked by increases in MDZ AUC exceeding 5-fold. For other CYPs and $A B C B 1$, the guidelines suggest that increases in the AUC of specific probes (e.g., warfarin, CYP2C9; omeprazole, CYP2C19; dextromethorphan, CYP2D6; digoxin, ABCB1) of 2-fold or higher may constitute clinically significant interactions. Rifampin was identified as an acceptable probe for examining the induction of CYP2B6, CYP2C8, CYP2C9, CYP2C19, CYP3A4, and $A B C B 1$. A reduction in the AUC values of substrates by $30 \%$ or greater would constitute a significant induction interaction. For drugs with narrow therapeutic indices, demonstration of a potentially "weak" interaction by a botanical could result in significant adverse side effects. Therefore, for purposes of this review, botanical formulations producing increases in probe drug AUCs of 2-fold will be classified as "clinically significant" inhibitors, and those reducing probe drug AUCs by $25 \%$ or more will be considered "clinically significant" inducers $[163,164]$.

One final limitation of clinical studies is that they can be costly, and it is often difficult to obtain mechanistic information. Nevertheless, clinical studies represent the only reliable means for realistically assessing a botanical supplement's herb-drug interaction potential $[137,138]$.

\section{Adulterants and Contamination \\ $\nabla$}

Dietary supplements have also faced challenges with regard to contamination and adulteration. Contamination with heavy metals, microbial pathogens, pesticide residues, and improperly identified plant material, as well as adulteration with toxic plant extracts, pharmaceutical agents, and other inappropriate additives have generated concern among the medical community and lay public [165]. While contamination or adulteration with less noxious substances or botanicals may not be harmful, other additives have been the cause of serious toxicity [166]. Contamination with heavy metals and various toxic herbs is generally more problematic for imported supplements than those produced domestically [167]. More disconcerting than unintended product contamination has been the seemingly purposeful adulteration of dietary supplements with conventional drugs [168, 169]. The FDA has removed a variety of dietary supplements from the market containing undeclared prescription medications and anabolic steroids, several of which have produced toxic manifestations in some consumers [170]. Most supplement manufacturers have avoided this problem through rigorous, proactive implementation of GMPs. Others, however, have been less sedulous in their approach to product quality. Beginning in 2008, the FDA implemented GMPs for supplements, addressing issues with species identification, contamination, and adulteration. Under the GMPs, adulterants continue to be illegal, and testing for certain contaminants is now required. Implementation of these regulations should significantly reduce incidences of adulteration and contamination. Nevertheless, from an herb-drug interaction perspective, effects attributable to botanicals must be differentiated from those produced by adulterants.

\section{Conclusion \\ $\nabla$}

Millions of years of "plant-animal warfare" have led to a complex and proficient system of human XMEs and transporters working in concert to preclude absorption and facilitate elimination of numerous structurally diverse dietary phytochemicals. Against the background of this efficient protective mechanism, botanical extracts and their resident PSMs have been used as medicinal agents for thousands of years becoming cultural mainstays throughout the world. Following World War II and the advent of the modern pharmaceutical industry, single-ingredient drug products quickly displaced botanicals from the pharmacopoeias of most Western societies. An appreciation for drug-drug interactions gradually emerged over the next 50 years, but not until the resurgence of botanical supplement use in 1994 did a concern for herb-drug interactions develop. For the last decade, predicting the likelihood and magnitude of herb-drug interactions has been a significant research focus within the scientific community. As will be demonstrated in the second part of this review, many PSMs modulate human XMEs and transporters in vitro, but due to various factors, this activity is rarely realized in vivo. Nevertheless, select PSMs when ingested concomitantly with prescription medications can dramatically affect human drug disposition giving rise to either reduced drug efficacy or clinically significant episodes of drug toxicity.

\section{Conflict of Interest \\ $\nabla$}

The authors declare no conflicts of interest.

\section{References}

1 Gonzalez FJ, Nebert DW. Evolution of the P450 gene superfamily: animal-plant "warfare," molecular drive and human genetic differences in drug oxidation. Trends Genet 1990; 60: 265-271

2 Nebert DW, Nelson DR, Feyereisen R. Evolution of the cytochrome P450 genes. Xenobiotica 1989; 19: 1149-1160

3 Bock KW. Veterbrate UDP-glucuronosyl transferases: functional and evolutionary aspects. Biochem Pharmacol 2003; 66: 691-696

4 Paulsen IT. Multidrug efflux pumps and resistance: regulation and evolution. Curr Opin Microbiol 2003; 6: 446-451

5 Iyer M, Reschly EJ, Krasowski MD. Functional evolution of the pregnane X receptor. Expert Opin Drug Metab Toxicol 2006; 2: 381-397

6 Makkar HPS, Siddhuraju P, Becker K. Plant secondary metabolites. Totowa: Humana Press; 2007 
7 Harbone JB, Baxter H, Moss GP. Phytochemical dictionary: a handbook of bioactive compounds from plants, 2nd edition. Philadelphia: Taylor \& Francis; 1999

8 Briskin DP. Medicinal plants and phytomedicines. Linking plant biochemistry and physiology to human health. Plant Physiol 2000; 124 : 507-514

9 Dixon RA. Natural products and plant disease resistance. Nature 2001; 411: 843-847

10 Nielsen KA, Moller BL. Cytochrome P450s in plants. In: Ortiz de Montellano PR, editor. Cytochrome P450: Structure, mechanism, and biochemistry, 3rd edition. New York: Kluwer Academic/Plenum; 2005: 553-583

11 Ross J, Li Y, Lim E, Bowles DJ. Higher plant glycosyltransferases. Genome Biol 2001; 2: 3004.1-3004.6

12 Bowles D, Isayenkova J, Lim E, Poppenberger B. Glycosyltransferases: managers of small molecules. Curr Opin Plant Biol 2005; 8: 254-263

13 Bowles D, Lim E-K, Poppenberger B, Vaistij FE. Glycosyltransferases of lipophilic small molecules. Annu Rev Plant Biol 2006; 57: 567-597

14 Varin L, Marsolais F, Richard M, Rouleau M. Biochemistry and molecular biology of plant sulfotransferases. FASEB J 1997; 11: 517-525

15 Dixon DP, Lapthorn A, Edwards R. Plant glutathione transferases. Genome Biol. 2002; 3: 3004.1-3004.10

16 Bowles SB, Yu Q. Evolution in action: plants resistant to herbicides. Annu Rev Plant Biol 2010; 61: 317-347

17 Siminszky B. Plant cytochrome P450-mediated herbicide metabolism. Phytochem Rev 2006; 5: 445-458

18 Yazaki K, Shitan N, Sugiyama A, Takanashi K. Cell and molecular biology of ATP-binding cassette proteins in plants. Int Rev Cell Mol Biol 2009; 276: 263-299

19 Yazaki K. Transporters of secondary metabolites. Curr Opin Plant Biol 2005; 8: 301-307

20 Sundberg BE, Waag E, Jacobsson JA, Stephansson O, Rumaks J, Svirskis S, Alsio J, Roman E, Ebendal T, Klusa V, Fredriksson $R$. The evolutionary history and tissue mapping of amino acid transporters belonging to solute carrier families SLC32, SLC36, and SLC38. J Mol Neurosci 2008; 35: 179-193

21 Kufner I, Koch $W$. Stress regulated members of the plant organic cation transporter family are localized to the vacuolar membrane. BMC Res Notes 2008; 43: 1-10

22 Danielson $P B$. The cytochrome P450 superfamily: biochemistry, evolution and drug metabolism in humans. Curr Drug Metab 2002; 3: 561597

23 Radominska-Pandya A, Czernik PJ, Little JM, Battaglia E, Mackenzie PI. Structural and functional studies of UDP-glucuronosyltransferases. Drug Metab Rev 1999; 31: 817-899

24 Eaton DL, Bammler TK. Concise review of the glutathione s-transferases and their significance to toxicology. Toxicol Sci 1999; 49: 156-164

25 Huang $C$, Chen $Y$, Zhou T, Chen G. Sulfation of dietary flavonoids by human sulfotransferases. Xenobiotica 2009; 39: 312-322

26 Kauffman FC. Sulfonation in pharmacology and toxicology. Drug Metab Rev 2004; 36: 823-843

27 Klaassen CD, Aleksunes LM. Xenobiotic, bile acid, and cholesterol transporters: function and regulation. Pharmacol Rev 2010; 62: 1-96

28 Jones PM, O'Mara ML, George AM. ABC transporters: a riddle wrapped in a mystery inside an enigma. TIBS 2009; 34: 520-531

29 Scherrmann JM. Transporters in absorption, distribution, and elimination. Chem Biodivers 2009; 6: 1933-1942

30 Ho RH, Kim RB. Transporters and drug therapy: implications for drug disposition and disease. Clin Pharmacol Ther 2005; 78: 260-277

31 Lewis DFV, Watson E, Lake BG. Evolution of the cytochrome P450 superfamily: sequence alignments and pharmacogenetics. Mutat Res 1998; 410: $245-270$

32 Schuler MA, Duan H, Bilgin M, Ali S. Arabidopis cytochrome P450s through the looking glass: a window on plant biochemistry. Phytochem Rev 2006; 5: 205-237

33 Mandlekar S, Hong JL, Kong AN. Modulation of metabolic enzymes by dietary phytochemicals: a review of mechanisms underlying beneficial versus unfavorable effects. Curr Drug Metab 2006; 7: 661-675

34 Li Y, Revalde JL, Reid G, Paxton JW. Interactions of dietary phytochemicals with $\mathrm{ABC}$ transporters: possible implications for drug disposition and multidrug resistance in cancer. Drug Metab Rev 2010; 42: 590611

35 Hernandez JP, Mota LC, Baldwin WS. Activation of CAR and PXR by dietary, environmental and occupational chemicals alters drug metabo- lism, intermediary metabolism, and cell proliferation. Curr Pharmacogenomic Person Med 2009; 7: 81-105

$36 \mathrm{Ma} \mathrm{O}$. Xenobiotic-activated receptors: from transcription to drug metabolism to disease. Chem Res Toxicol 2008; 21: 1651-1671

37 Pascussi JM, Gerbal-Chaloin S, Duret C, Daujat-Chavanieu M, Vilarem MJ Maurel $P$. The tangle of nuclear receptors that controls xenobiotic metabolism and transport: crosstalk and consequences. Annu Rev Pharmacol Toxicol 2008; 48: 1-32

38 Gonzalez FJ. The 2006 Bernard B. Brodie Award Lecture: CYP2E1. Drug Metab Dispos 2007; 35: 1-8

39 Clarke JD, Dashwood RH, Ho E. Multi-targeted prevention of cancer by sulforaphane. Cancer Lett 2008; 269: 291-304

40 Farkas D, Greenblat DJ. Influence of fruit juices on drug disposition: discrepancies between in vitro and clinical studies. Expert Opin Drug Metab Toxicol 2008; 4: 381-393

41 Schmiedlin-Ren P, Edwards DJ, Fitzsimmons ME, He K, Lown KS, Woster PM, Rahman A, Thummel KE, Fisher JM, Hollenberg PF, Watkins PB. Mechanisms of enhanced oral availability of CYP3A4 substrates by grapefruit constituents: decreased enterocyte CYP3A4 concentration and mechanism-based inactivation by furanocoumarins. Drug Metab Dispos 1997; 25: 1228-1233

42 Guengerich FP, Kim DH, Iwasaki M. Role of human cytochrome P-450 IIE1 in the oxidation of many low molecular weight cancer suspects. Chem Res Toxicol 1991; 4: 168-179

43 Yang CS, Yoo JS, Ishizaki H, Hong JY. Cytochrome P450IIE1: roles in nitrosamine metabolism and mechanisms of regulation. Drug Metab Rev 1990; 22: 147-159

44 Yang CS, Chhabra SK, Hong JY, Smith TJ. Mechanisms of inhibition of chemical toxicity and carcinogenesis by diallyl sulfide (DAS) and related compounds from garlic. J Nutr 2001; 131: 1041S-1045S

45 Park KA, Kweon S, Choi $\mathrm{H}$. Anticarcinogenic effect and modification of cytochrome P4502E1 by dietary garlic powder in diethylnitrosamineinitiated rat hepatocarcinogenesis. J Biochem Mol Biol 2002; 35: 615622

46 Gurley BJ, Gardner SF, Hubbard MA, Williams DK, Gentry WB, Cui Y, Ang $C Y W$. Cytochrome $\mathrm{P} 450$ phenotypic ratios for predicting herb-drug interactions in humans. Clin Pharmacol Ther 2002; 72: 276-287

47 Leclercq I, Desager JP, Horsmans Y. Inhibition of chlorzoxazone metabolism, a clinical probe for CYP2E1, by a single ingestion of watercress. Clin Pharmacol Ther 1998; 64: 144-149

48 Zhang $Y$, Talalay P. Anticarcinogenic activities of organic isothiocyanates: chemistry and mechanisms. Cancer Res 1994; 54: 1976s-1981s

49 Gonzalez FJ, Gelboin HV. Role of human cytochromes P450 in the metabolic activation of chemical carcinogens and toxins. Drug Metab Rev 1994; 26: 165-183

50 Nebert DW. Polymorphisms in drug-metabolizing enzymes: what is their clinical relevance and why do they exist? Am J Hum Genet 1997; 60: 265-271

51 Neafsey P, Ginsberg G, Hattis D, Sonawane B. Genetic polymorphism in cytochrome P450 2D6 (CYP2D6): population distribution of CYP2D6 activity. J Toxicol Environ Health B 2009; 12: 334-361

52 Lewis DFV, Eddershaw PJ, Goldfarb PS, Tarbit MH. Molecular modeling of cytochrome P4502D6 (CYP2D6) based on an alignment with CYP102: structural studies on specific CYP2D6 substrate metabolism. Xenobiotica 1997; 27: 319-340

53 Ingelman-Sundberg M. Genetic polymorphisms of cytochrome P450 2D6 (CYP2D6): clinical consequences, evolutionary aspects and functional diversity. Pharmacogenomics J 2005; 5: 6-13

54 Sullivan RJ, Hagen EH, Hammerstein P. Revealing the paradox of drug reward in human evolution. Proc Biol Sci 2008; 275: 1231-1241

55 Ingelman-Sundberg $M$. The human genome project and novel aspects of cytochrome P450 research. Toxicol Appl Pharmacol 2005; 207: S52S56

56 Schmidt B, Ribnicky DM, Poulev A, Logendra S, Cefalu WT, Raskin I. A natural history of botanical therapeutics. Metab Clin Exp 2008; 57: S3-S9

57 Craig WJ. Phytochemicals: guardians of our health. J Am Diet Assoc 1997; 97: S199-S204

$58 \mathrm{Hu}$ FB. Plant-based foods and prevention of cardiovascular disease: an overview. Am J Clin Nutr 2003; 78: 544S-551S

59 Heber D. Vegetables, fruits and phytoestrogens in the prevention of diseases. J Postgrad Med 2004; 50: 145-149

60 Graf BA, Milbury PE, Blumberg JB. Flavonols, flavones, flavanones, and human health: epidemiological evidence. J Med Food 2005; 8: 281290 
61 Thomasset SC, Berry DP, Garcea G, Marczylo T, Steward WP, Gescher AJ. Dietary polyphenolic phytochemicals-promising cancer chemopreventative agents in humans? A review of their clinical properties. Int J Cancer 2006; 120: 451-458

$62 \mathrm{Kim}$ J, Lee HJ, Lee KW. Naturally occurring phytochemicals for the prevention of Alzheimer's disease. J Neurochem 2010; 112: 1415-1430

63 Dietary Supplement Health and Education Act (DSHEA), Public Law 103-417, 1994; Act 42 U.S.C. 287C-11

64 Gurley BJ. Clinical pharmacology and dietary supplements: an evolving relationship. Clin Pharmacol Ther 2010; 87: 235-238

65 Barnes PM, Bloom B. Complementary and alternative medicine use among adults and children: United States, 2007. National Health Statistics Reports No 12. Hyattsville: US Department of Health and Human Services; 2008

66 Nahin RL, Barnes PM, Stussman BJ, Bloom B. Costs of complementary and alternative medicine (CAM) and frequency of visits to CAM practitioners: United States, 2007. National Health Statistics Reports No 18. Hyattsville: US Department of Health and Human Services; 2009

67 Gardiner P, Graham RE, Legedza AT, Eisenberg DM, Phillips RS. Factors associated with dietary supplement use among prescription medication users. Arch Intern Med 2006; 166: 1968-1974

68 Wold RS, Lopez ST, Yau L, Butler LM, Pareo-Tubbeh SL, Waters DL, Garry $P J$, Baumgartner RN. Increasing trends in elderly persons' use of nonvitamin, nonmineral dietary supplements and concurrent use of medications. J Am Diet Assoc 2005; 105: 54-63

69 Qato DM, Alexander GC, Conti RM, Johnson M, Schumm P, Lindau ST. Use of prescription and over-the-counter medications and dietary supplements among older adults in the United States. JAMA 2008; 300: $2867-$ 2878

70 Bruno JJ, Ellis JJ. Herbal use among US elderly: 2002 National Health Interview Survey. Ann Pharmacother 2005; 39: 643-648

71 AARP, NCCAM. What people 50 and older are using and discussing with their physicians. Washington DC: AARP; 2007

72 Kishiyama SS, Leahy MJ, Zitzelberger TA, Guariglia R, Zajdel DP, Calvert JF, Kaye JA, Oken BS. Patterns of dietary supplement usage in demographically diverse older people. Altern Ther Health Med 2005; 11: 48-53

73 Foster DF, Phillips RS, Hamel MB, Eisneberg DM. Alternative medicine use in older Americans. J Am Geriatr Soc 2000; 48: 1560-1565

74 Mehta DH, Gardiner PM, Phillips RS, McCarthy EP. Herbal and dietary supplement disclosure to health care providers by individuals with chronic conditions. J Altern Complement Med 2008; 14: 1263-1269

75 Paine MF, Ludington SS, Chen ML, Stewart PW, Huang SM, Watkins PB. Do men and women differ in proximal small intestinal CYP3A or P-glycoprotein expression? Drug Metab Dispos 2005; 33: 426-433

76 Canaparo R, Finnstrom N, Serpe L, Nordmark A, Muntoni E, Eandi M, Rane A, Zara GP. Expression of CYP3A isoforms and p-glycoprotein in human stomach, jejunum and ileum. Clin Exp Pharmacol Physiol 2007: $34: 1138-1144$

77 Niemi M. Role of OATP transporters in the disposition of drugs. Pharmacogenomics 2007; 8: 787-802

78 Tomlinson B, Hu M, Lee VWY. In vivo assessment of herb-drug interactions: possible utility of a pharmacogenetic approach? Mol Nutr Food Res 2008; 52: 799-809

79 Yin OQP, Tomlinson B, Waye MMY, Chow AHL, Chow MSS. Pharmacogenetics and herb-drug interactions: experience with Ginkgo biloba and omeprazole. Pharmacogenetics 2004; 14: 841-850

80 Yang LJ, Fan L, Liu ZQ Mao YM, Guo D, Liu LH, Tan ZR, Peng L, Han CT, Hu $D L$, Wang D, Zhou HH. Effects of allicin on CYP2C19 and CYP3A4 activity in healthy volunteers with different CYP2C19 genotypes. Eur J Clin Pharmacol 2009; 65: 601-608

81 Han Y, Guo D, Chen Y, Chen Y, Tan ZR, Zhou HH. Effect of silymarin on the pharmacokinetics of losartan and its active metabolite E-3174 in healthy Chinese volunteers. Eur J Clin Pharmacol 2009; 65: 585-591

82 Williamson EM. Synergy and other interactions in phytomedicines. Phytomedicine 2001; 8: 401-409

83 Gilbert B, Alves LF. Synergy in plant medicines. Curr Med Chem 2003; 10: $13-20$

84 Obach RS. Inhibition of human cytochrome P450 enzymes by constituents of St. John's wort, an herbal preparation used in the treatment of depression. J Pharmacol Exp Ther 2000; 29: 88-95

85 Budzinski JW, Foster BC, Vandenhoek S, Arnason JT. An in vitro evaluation of human cytochrome P450 3A4 inhibition by selected commercial herbal extracts and tinctures. Phytomedicine 2000; 7: 273-282
86 Zou L, Harkey MR, Henderson GL. Effects of herbal components on cDNA-expressed cytochrome P450 enzyme catalytic activity. Life Sci 2002; 71: 1579-1589

87 Mathews JM, Etheridge AS, Black SR. Inhibition of human cytochrome P450 activities by kava extract and kava lactones. Drug Metab Dispos 2002; 30: 1153-1157

88 Foster BC, Vandenhoek S, Hana J, Krantis A, Akhtar MH, Bryan M, Budzinski JW, Ramputh A, Arnason JT. In vitro inhibition of human cytochrome P450-mediated metabolism of marker substrates by natural products. Phytomedicine 2003; 10: 334-342

89 Raucy JL. Regulation of CYP3A4 expression in human hepatocytes by pharmaceuticals and natural products. Drug Metab Dispos 2003; 31 : 533-539

90 Chatterjee P, Franklin MR. Human cytochrome P450 inhibition and metabolic-intermediate complex formation by goldenseal extract and its methylenedioxyphenyl components. Drug Metab Dispos 2003; 31: 1391-1397

91 Iwata H, Tezuka Y, Usia T, Kadota S, Hiratsuka A, Watabe T. Inhibition of human liver microsomal CYP3A4 and CYP2D6 by extracts from 78 herbal medicines. J Tradit Med 2004; 21: 42-50

92 Unger M, Frank A. Simultaneous determination of the inhibitory potency of herbal extracts on the activity of six major cytochrome P450 enzymes using liquid chromatography/mass spectrometry and automated online extraction. Rapid Commun Mass Spectrom 2004; 18: 2273-2281

$93 \mathrm{He}$, Edeki T. The inhibitory effects of herbal components on CYP2C9 and CYP3A4 catalytic activities in human liver microsomes. Am J Ther 2004; 11: 206-212

94 Zou L, Henderson GL, Harkey MR, Sakai Y, Li A. Effects of kava (kava-kava, 'Awa, Yaqona, Piper methysticum) on c-DNA-expressed cytochrome P450 enzymes and human cryopreserved hepatocytes. Phytomedicine 2004; 11: 285-294

95 Strandell J, Neil A, Carlin G. An approach to the in vitro evaluation of potential for cytochrome P450 enzyme inhibition from herbals and other natural remedies. Phytomedicine 2004; 11: 98-104

96 Gross-Steinmeyer K, Stapleton PL, Liu F, Tracy JH, Bammler TK, Quigley $S D$, Farin FM, Buhler DR, Safe SH, Strom SC, Eaton DL. Phytochemicalinduced changes in gene expression of carcinogen-metabolizing enzymes in cultured human primary hepatocytes. Xenobiotica 2004; 34: 619-632

97 von Moltke LL, Weemhoff JL, Bedir E, Khan IA, Harmatz JS, Goldman P, Greenblatt DJ. Inhibition of human cytochromes $\mathrm{P} 450$ by components of Ginkgo biloba. J Pharm Pharmacol 2004; 56: 1039-1044

98 Iwata H, Tezuka Y, Kadota S, Hiratuska A, Watabe T. Identification and characterization of potent CYP3A4 inhibitors in Schisandra fruit extract. Drug Metab Dispos 2004; 32: 1351-1358

99 Whitley AC, Sweet $D H$, Walle T. The dietary polyphenol ellagic acid is a potent inhibitor of hOAT1. Drug Metab Dispos 2005; 33: 1097-1100

100 Yale SH, Glurich I. Analysis of the inhibitory potential of Ginkgo biloba, Echinacea purpurea, and Serenoa repens on the metabolic activity of cytochrome P450 3A4, 2D6, and 2C9. J Altern Complement Med 2005; 11: 433-439

101 Scott IM, Leduc RI, Burt AJ, Marles RJ, Arnason JT, Foster BC. The inhibition of human cytochrome P450 by ethanol extracts of North American botanicals. Pharm Biol 2006; 44: 315-327

102 Fuchikami H, Satoh H, Tsujimoto M, Ohdo S, Ohtani H, Sawada Y. Effects of herbal extracts on the function of human organic anion-transporting polypeptide OATP-B. Drug Metab Dispos 2006; 34: 577-582

103 Foti RS, Wahlstrom JL, Wienkers LC. The in vitro drug interaction potential of dietary supplements containing multiple herbal components. Drug Metab Dispos 2007; 35: 185-188

104 Lee SS, Zhang B, He ML, Chang VSC, Kung HF. Screening of active ingredients of herbal medicine for interaction with CYP450 3A4. Phytother Res 2007; 21: 1096-1099

105 Etheridge AS, Black SR, Patel PR, So J, Mathews JM. An in vitro evaluation of cytochrome P450 inhibition and P-glycoprotein interaction with goldenseal, Ginkgo biloba, grape seed, milk thistle, and ginseng extracts and their constituents. Planta Med 2007; 73: 731-741

106 Raner GM, Cornelious S, Moulick K, Wang Y, Mortensen A, Cech NB. Effects of herbal products and their constituents on human P4502E1 activity. Food Chem Toxicol 2007; 45: 2359-2365

107 Hellum BH, Hu Z, Nilsen OG. The induction of CYP1A2, CYP2D6 and CYP3A4 by six trade herbal products in cultured primary human hepatocytes. Basic Clin Pharmacol Toxicol 2007; 100: 23-30 
108 Hellum BH, Nilsen OG. The in vitro inhibitory potential of trade herbal products on huan CYP2D6-mediated metabolism and the influence of ethanol. Basic Clin Pharmacol Toxicol 2007; 101: 350-358

109 Budzinski JW, Trudeau VL, Drouin CE, Panahi M, Arnason JT, Foster BC. Modulation of human cytochrome P450 3A4 (CYP3A4) and P-glycoprotein (P-gp) in Caco-2 cell monolayers by selected commercialsource milk thistle and goldenseal products. Can J Physiol Pharmacol 2007; 85: 966-978

110 Budzinski JW, Foster BC, Trudeau VL, Drouin CE, Bafi-Yeboa N, Arnason $J T$. The interaction of selected phytochemicals, HIV drugs, and commercial-source herbal teas and capsules with human cytochrome P450 3A4 and P-glycoprotein. Pharm Biol 2008; 46: 53-65

111 Hellum BH, Nilsen OG. In vitro inhibition of CYP3A4 metabolism and Pglycoprotein-mediated transport by trade herbal products. Basic Clin Pharmacol Toxicol 2008; 102: 466-475

112 Engdal S, Nilsen OG. Inhibition of P-glycoprotein in Caco-2 cells: effects of herbal remedies frequently used by cancer patients. Xenobiotica 2008; 38: 559-573

113 Satsu H, Hiura Y, Mochizuki K, Hamada M, Shimizu M. Activation of pregnane $\mathrm{X}$ receptor and induction of MDR1 by dietary phytochemicals. J Agric Food Chem 2008; 56: 5366-5373

114 Roderio I, Donato MT, Jimenez N, Garrido G, Molina-Torres J, Menendez R, Castell JV, Gomez-Lechon MJ. Inhibition of human P450 enzymes by natural extracts used in traditional medicine. Phytother Res 2009; 23: 279-282

115 Hellum BH, Hu Z, Nilsen OG. Trade herbal products and induction of CYP2C19 and CYP2E1 in cultured human hepatocytes. Basic Clin Pharmacol Toxicol 2009; 105: 58-63

116 Tiong KH, Yiap BC, Tan EL, Ismail R, Ong CE. In vitro modulation of naturally occurring flavonoids on cytochrome P450 2A6 (CYP2A6) activity. Xenobiotica 2010; 40: 458-466

117 Satsu H, Hiura Y, Mochizuki K, Hamada M, Shimizu M. Activation of pregnane $\mathrm{X}$ receptor and induction of MDR1 by dietary phytochemicals. J Agric Food Chem 2008; 56: 5366-5373

118 Okura T, Ibe M, Umegaki K, Shinozuka K, Yamada S. Effects of dietary ingredients on function and expression of P-glycoprotein in human intestinal epithelial cells. Biol Pharm Bull 2010; 33: 255-259

119 Najar IA, Sachin BS, Sharma SC, Satti NK, Suri KA, Johri RK. Modulation of P-glycoprotein ATPase activity by some phytoconstituents. Phytother Res 2010; 24 : 454-458

120 Kimura $Y$, Ito $H$, Ohnishi R, Hatano T. Inhibitory effects of polyphenols on human cytochrome P450 3A4 and 2C9 activity. Food Chem Toxicol 2010; 48: 429-435

121 Sevior DK, Hokkanen J, Tolonen A, Abass K, Tursas L, Pelkonen O, Ahokas $J T$. Rapid screening of commercially available herbal products for the inhibition of major human hepatic cytochrome P450 enzymes using the N-in-one cocktail. Xenobiotica 2010; 40: 245-254

122 Nahrstedt A, Butterweck $V$. Lessons learned from herbal medicinal products: the example of St John's wort. J Nat Prod 2010; 73: 10151021

123 Gurley BJ, Gardner SF, Hubbard MA. Content versus label claims in ephedra-containing dietary supplements. Am J Health Syst Pharm 2000; 57: 963-969

124 Harkey MR, Henderson GL, Gershwin ME, Stern JS, Hackman RM. Variability in commercial ginseng products: an analysis of 25 preparations. Am J Clin Nutr 2001; 73: 1101-1106

125 Garrard J, Harms S, Eberly LE, Matiak A. Variations in product choices of frequently purchased herbs. Arch Intern Med 2003; 163: 22902295

126 Brinker $F$. Managing and interpreting the complexities of botanical research. HerbalGram 2009; 82: 42-49

127 Hines $E$. Standardizing botanical extracts: can the part exceed the whole? Pharm Formul Qual 1999; 3: 28-33

128 van Breeman RB, Fong HHS, Farnsworth NR. Ensuring the safety of botanical dietary supplements. Am J Clin Nutr. 2008; 87: 509S-513S

129 Goldman P. Herbal medicines today and the roots of modern pharmacology. Ann Intern Med 2001; 135: 594-600

130 Wanwimolruk S, Wong K, Wanwimolruk P. Variable inhibitory effect of different brands of commercial herbal supplements on human cytochrome P-450 CYP3A4. Drug Metab Drug Interact 2009; 24: 17-35

131 Gurley BJ. Dosage form performance: an overlooked determinant of phytochemical efficacy and safety. Planta Med 2010; 76: 504

132 Schulz HU, Schurer M, Krumbiegel G, Wachter W, Weyhenmeyer R, Seidel $G$. Investigation of dissolution and bioequivalence of silymarin products. Arzneimittelforschung 1995; 45: 61-64
133 Westerhoff K, Kaunzinger A, Wurglics M, Dressman J, Schubert-Zsilavecz $M$. Biorelevant dissolution testing of St John's wort products. J Pharm Pharmacol 2002; 54: 1615-1621

134 Nair VDP, Kanfer I. Development of dissolution tests for the quality control of complementary/alternate and traditional medicines: application to African potato products. J Pharm Pharm Sci 2008; 11: 35-44

135 United States Pharmacopeial Convention. Disintegration and dissolution of dietary supplements. Rockville: USP 33-NF 28; 2010

136 Current good manufacturing practice in manufacturing, packaging, labeling, or holding operations for dietary supplements; Final rule. Fed Reg 2007; 72: 34751-34958

137 Venkataramanan $R$, Komoroski B, Strom S. In vitro and in vivo assessment of herb drug interactions. Life Sci 2006; 78: 2105-2115

138 Markowitz JS, von Moltke LL, Donovan JL. Predicting interactions between conventional medications and botanical products on the basis of in vitro investigations. Mol Nutr Food Res 2008; 52: 747-754

139 Ruschitzka F, Meier PJ, Turina M, Luscher TF, Noll G. Acute heart transplant rejection due to Saint John's wort. Lancet 2000; 355: 548-549

140 Breidenbach TH. Profound drop of cyclosporine A whole blood trough levels caused by St. John's wort (Hypericum perforatum). Transplantation 2000; 69: 2229-2232

141 Barone GW, Gurley BJ, Ketel BL, Lightfoot ML, Abul-Ezz SR. Drug interaction between St John's wort and cyclosporine. Ann Pharmacother 2000; 34: 1013-1016

142 Barone GW, Gurley BJ, Ketel BL, Abul-Ezz SR. Herbal dietary supplements: a source for drug interactions in transplant recipients. Transplantation 2001; 71: 239-241

143 Moore LB, Goodwin B, Jones SA, Wisely WB, Serabjit-Singh CJ, Willson $T M$, Collins JL, Kliewer SA. St John's wort induces hepatic drug metabolism through activation of the pregnane X receptor. Proc Natl Acad Sci USA 2000; 97: 7500-7502

144 Wentworth JM, Agostini M, Love J, Schwabe JW, Chatterjee VKK. St John's wort, a herbal antidepressant, activates the steroid X receptor. J Endocrinol 2000; 166: R11-R16

145 Johne A, Brockmöller J, Bauer S, Maurer A, Langheinrich M, Roots I. Pharmacokinetic interaction of digoxin with an herbal extract from St John's wort (Hypericum perforatum). Clin Pharmacol Ther 1999; 66: $338-345$

146 Roby CA, Anderson GD, Kantor E, Dryer DA, Burstein AH. St John's wort: effect on CYP3A4 activity. Clin Pharmacol Ther 2000; 67: 451-457

147 Wang Z, Gorski C, Hamman MA, Huang SM, Lesko LJ, Hall SD. The effects of St John's wort (Hypericum perforatum) on human cytochrome P450 activity. Clin Pharmacol Ther 2001; 70: 317-326

148 Sugimoto K, Ohmori M, Tsuruoka S, Nishiki K, Kawaguchi A, Harada K, Arakawa M, Sakamoto K, Masada M, Miyamori I, Fujimura A. Different effects of St John's wort on the pharmacokinetics of simvastatin and pravastatin. Clin Pharmacol Ther 2001; 70: 518-524

149 Hennessy M, Kelleher D, Spiers JP, Kavanagh BP, Back D, Mulcahy F, Feely $J$. St John's wort increases expression of P-glycoprotein: implications for drug interactions. Br J Clin Pharmacol 2002; 53: 75-82

150 Izzo AA. Herb-drug interactions: an overview of the clinical evidence. Fund Clin Pharmacol 2004; 19: 1-16

151 Zhou S, Lim LY, Chowbay B. Herbal modulation of P-glycoprotein. Drug Metab Rev 2004; 36: 57-104

152 Delogda R, Westlake ACG. Herbal interactions involving cytochrome P450 enzymes. Toxicol Rev 2004; 23: 239-249

153 Mills E, Wu P, Johnston BC, Gallicano K, Clarke M, Guyatt G. Natural health product-drug interactions: a systematic review of clinical trials. Ther Drug Monit 2005; 27: 549-557

154 Hu Z, Yang X, Ho PCL, Chan SY, Heng PWS, Chan E, Duan W, Koh HL, Zhou S. Herb-drug interactions: a literature review. Drugs 2005; 65: $1239-1282$

155 Johne A, Roots I. Clinical drug interactions with medicinal herbs. Evid Based Integr Med 2005; 2: 207-228

156 Ulbricht C, Basch E, Weissner W, Hackman D. An evidence-based systematic review of herb and supplement interactions by the Natural Standard Research Collaboration. Expert Opin Drug Saf 2006; 5: 719-728

157 Borrelli F, Capasso R, Izzo AA. Garlic (Allium sativum L.): adverse effects and drug interactions in humans. Mol Nutr Food Res 2007; 51: 13861397

158 Borrelli F, Izzo AA. Herb-drug interactions with St John's wort (Hypericum perforatum): an update on clinical observations. AAPS J 2009; 11: $710-727$ 
159 Izzo AA, Ernst E. Interactions between herbal medicines and prescribed drugs: an updated systematic review. Drugs 2009; 69: 17771798

160 Kennedy DA, Seely D. Clinically based evidence of drug-herb interactions: a systematic review. Expert Opin Drug Saf 2010; 9: 79-124

161 Gurley B, Hubbard MA, Williams DK, Thaden J, Tong Y, Gentry WB, Breen $P$, Carrier DJ, Cheboyina S. Assessing the clinical significance of botanical supplementation on human cytochrome P450 3A activity: comparison of a milk thistle and black cohosh product to rifampin and clarithromycin. J Clin Pharmacol 2006; 46: 201-213

162 Gurley BJ, Swain A, Williams DK, Barone G, Battu SK. Gauging the clinical significance of P-glycoprotein-mediated herb-drug interactions: comparative effects of St John's wort, echinacea, clarithromycin, and rifampin on digoxin pharmacokinetics. Mol Nutr Food Res 2008; 52: 772-779

163 Food and Drug Administration. Drug Interaction Studies-Study Design, Data Analysis, and Implications for Dosing and Labeling. Available at http://www.fda.gov/Drugs/Guidance Compliance Regulatory Information/Guidances/ucm064982.htm. Accessed October 11, 2011
164 Huang SM, Temple R, Throckmorton DC, Lesko LJ. Drug interaction studies: study design, data analysis, and implications for dosing and labeling. Clin Pharmacol Ther 2007; 81: 298-304

165 Smolinske SC. Herbal product contamination and toxicity. J Pharm Pract 2005; 18: 188-208

166 Ko R. Safety of ethnic \& imported herbal and dietary supplements. Clin Toxicol 2006; 44: 611-616

167 Cole MR, Fetrow CW. Adulteration of dietary supplements. Am J Health Syst Pharm 2003; 60: 1576-1580

168 Fleshner N, Harvey M, Adomat H, Wood C, Eberding A, Hersey K, Guns E. Evidence for contamination of herbal erectile dysfunction products with phosphodiesterase type 5 inhibitors. J Urol 2005; 174: 636-641

169 Food and Drug Administration. Warning on body building products marketed as containing steroids or steroid-like substances. US Department of Health and Human Services, Rockville, MD. Available at http://www.fda.gov/ForConsumers/ConsumerUPdates/ucm173739. html. Accessed October 11, 2011

170 Food and Drug Administration. More weight loss products added to consumer alert. US Department of Health and Human Services, Rockville, MD. Available at http://www.fda.gov/ForConsumers/ConsumerUpdates/ucm103184.htm. Accessed October 11, 2011 